\title{
OS IMPACTOS DO NOVO CÓDIGO DE PROCESSO CIVIL NO SISTEMA RECURSAL DOS JUIZADOS ESPECIAIS CÍVEIS
}

Thais Fernanda Silva Rogério, Israel Matheus Cardozo Silva Coutini, Fabiana Vergílio Souto, Rachel Lopes Queiroz Chacur.

Universidade do Oeste Paulista- UNOESTE, Curso de Direito, Presidente Prudente/SP. E-mail: thais fsr@hotmail.com

\section{RESUMO}

Objetiva o presente estudo a abordar os reflexos trazidos pelo novo Código de Processo Civil para o sistema recursal dos Juizados Especiais Cíveis, uma vez que a Lei no 9.099/95 é omissa em relação a várias matérias, aplicando-se, de forma subsidiária, o Código de Processo Civil. No mais, enfatiza as principais modificações trazidas pela nova legislação, que são compatíveis e adaptáveis à esfera recursal dos Juizados Especiais Cíveis, de forma a contribuir com as atividades de pesquisa no Curso de Direito, visando à participação dos alunos, numa perspectiva científica. Por fim, tendo em vista que o tema a ser apresentado possuí grande relevância no nosso ordenamento jurídico, torna-se imprescindível uma ampla e merecida discussão.

Palavras-chave: Novo Código de Processo Civil. Juizado Especial Cível. Recursos. Alterações. Aplicações.

THE NEW IMPACTS CIVIL PROCEDURE CODE IN THE SYSTEM OF SPECIAL COURTS APPELLATE CIVIL

\begin{abstract}
Objective this study to address the consequences brought by the new Code of Civil Procedure for the appeal system of the Small Claims Courts, since Law $n$ o 9.099/95 is silent on various subjects, applying, in a subsidiary way, Code of Civil Procedure. No more, it emphasizes the main changes brought by the new legislation, which are compatible and adaptable to appeal sphere of Small Claims Courts in order to contribute to research activities in the Law Course, aimed at participation of students from a scientific perspective. Finally, given that the topic being presented possess great relevance in our legal system, it is essential a wide and deserved discussion.
\end{abstract}

Keywords: New Civil Procedure Code. Special civil court. Resources. Changes. Applications. 


\section{INTRODUÇÃO}

Desde a criação dos Juizados Especiais Cíveis (JEC) em 1995, estes utilizavam-se do Código de Processo Civil de 1973, de forma subsidiária, para resolução das matérias não disciplinadas pela lei que o regula até então - a Lei no 9.099/95.

O fundamento do JEC encontra-se no art. 98, I, da Constituição Federal, incumbindo a Lei no 9.099/95 a dar cumprimento à determinação constitucional, com a finalidade de amplo acesso à justiça. Ademais, é sabido que os atos processuais são baseados nos princípios da oralidade, simplicidade, informalidade, economia processual e celeridade, conforme dispõe o artigo 20 da referida legislação, visando à conciliação ou à transação.

Vale ressaltar que com a edição da Lei no 13.105, de 16 de março de 2015, que apresenta uma nova legislação processual, algumas modificações foram efetivadas, refletindo-se também no sistema recursal do JEC, o qual possui, como meios próprios de impugnação, o recurso inominado, os embargos de declaração e o recurso extraordinário.

Fixadas tais asserções, o objetivo do presente estudo é abordar os impactos que o Novo Código de Processo Civil trouxe para os Juizados Especiais Cíveis no tocante à esfera recursal.

\section{METODOLOGIA}

A metodologia utilizada na pesquisa foi eminentemente bibliográfica, tendo a intenção de possibilitar a compreensão dos impactos que o Novo Código de Processo Civil trouxe ao Sistema Recursal dos Juizados Especiais Cíveis (Lei 9.099/95) e demonstrando as significantes aplicações.

Num estudo, partindo-se do raciocínio hipotético dedutivo, foram construídas as bases do projeto numa interpretação reflexiva e dialética.

\section{DISCUSSÃO \\ DOS JUIZADOS ESPECIAIS CÍVEIS}

Antes dos Juizados Especiais, fora editada, no Brasil, a Lei no 7.244, em 1984, isto é, os Juizados de Pequenas Causas, com a finalidade de simplificar e facilitar o acesso à justiça dos menos favorecidos. Posteriormente, em 1988, fora promulgada uma nova Constituição Federal, prevendo a criação de Juizados Especiais em seu art. 98, I. $^{1}$

Desta forma, em observância à exigência constitucional, uma nova lei fora editada, a Lei no 9.099, em 1995 (Juizados Especiais Cíveis e Criminais), substituindo a lei supracitada.

Mais tarde, surgiram as Leis no 10.259, em 2001 (Juizado Especial Federal), e no 12.153, em 2009 (Juizado Especial da Fazenda Pública), fundadas nos princípios da oralidade, simplicidade, informalidade, economia processual e celeridade, sustentando como principal finalidade a conciliação.

Assim, tem-se em vista que, desde a sua criação, o objetivo dos Juizados Especiais Cíveis é oferecer às partes uma justiça ágil, simples e menos formal, de modo a permitir que todas as demandas ingressem no judiciário, independentemente de baixo valor econômico ou de falta de complexidade.

\section{PRINCÍPIOS NOS JUIZADOS ESPECIAIS CÍVEIS}

Os princípios têm uma extrema importância no ordenamento jurídico brasileiro. Segundo Alexy (apud BARBOSA; BONIN, 2015, p. 632), "princípios são mandamentos de otimização,

\footnotetext{
${ }^{1}$ A União, no Distrito Federal e nos Territórios, e os Estados criarão: I- juizados especiais, providos por juízes togados, ou togados e leigos, competentes para a conciliação, o julgamento e a execução de causas cíveis de menor complexidade e infrações penais de menor potencial ofensivo, mediante os procedimentos oral e sumariíssimo, permitidos, nas hipóteses previstas em lei, a transação e o julgamento de recursos por turmas de juízes de primeiro grau.
} 
devendo os mesmos ser aplicados na máxima medida possível de acordo com as circunstâncias fáticas e jurídicas".

No que se refere ao JEC, os princípios encontram-se elencados no artigo 2으 da Lei ํㅡ 9.099/1995, "o processo orientar-se-á pelos critérios da oralidade, simplicidade, informalidade, economia processual e celeridade, buscando, sempre que possível à conciliação ou a transação."

Assim, tem-se em vista que o órgão em questão tem, como princípios orientadores, a oralidade, por meio do qual o maioria dos atos devem ser feitos de forma oral, promovendo o contato do juiz diretamente com a parte; a simplicidade, pelo qual se exige somente o que for necessário para o andamento do processo, sem maiores burocratizações; a informalidade, que se diz respeito à forma, sendo mais simplificada em relação à da Justiça Comum, visando a apresentar, à parte, rapidez e praticidade; a economia processual, resultando na redução dos atos processuais e, consequentemente, das custas; e, finalmente, a celeridade, com a finalidade de resolução rápida de conflitos.

Acrescenta-se, o legislador, com a edição do CPC/2015, fez referência aos princípios constitucionais e também positivou outros de natureza processual, conforme dispõe no artigo $1^{\circ}$. Desta forma, o CPC/2015 aborda, como princípios orientadores, a razoável duração do processo, a eficiência e a imparcialidade.

\section{EFEITOS RECURSAIS}

Os efeitos recursais no JEC constam no artigo 43 da Lei no 9.099/1995: “O recurso terá somente efeito devolutivo, podendo o Juiz dar-lhe efeito suspensivo, para evitar dano irreparável para a parte."

Observa-se, em caráter de exceção, que o juiz de primeiro grau poderá conceder efeito suspensivo ao recurso, de modo a evitar dano irreparável à parte. No mais, o Colégio Recursal também pode conceder o efeito suspensivo antes do julgamento.

Ressalte-se, o CPC/2015 trouxe, como uma de suas alterações, que a parte recorrente, ao desejar obter efeito suspensivo, bastará fazer simples requerimento, por meio de petição, atingindo também o JEC.

A regra no JEC continuará sendo o recurso recebido somente em efeito devolutivo, porém o procedimento adotado pela parte, para obtenção do efeito suspensivo, deverá ser o estabelecido no $\mathrm{CPC} / 2015$, ou seja, mediante requerimento.

\section{OS IMPACTOS DO NOVO CÓDIGO DE PROCESSO CIVIL NO SISTEMA RECURSAL DOS JUIZADOS ESPECIAIS CÍVEIS}

Com a edição da Lei no 13.105, de 16 de março de 2015, algumas modificações foram efetivadas no nosso ordenamento jurídico, refletindo também, ainda que de forma subsidiária, nos Juizados Especiais Cíveis.

Conforme os ensinamentos de Barbosa; Bonin (2015, p. 631):

Nesse ponto, cabe ressaltar as principais mudanças no sistema recursal atual, identificando, em sequência, o que de fato irá mudar nos Juizados Especiais. De forma geral, unificaram-se os prazos recursais para 15 (quinze) dias, com exceção dos embargos de declaração, e adotou-se como regra genérica para os efeitos recursais a não suspensividade. A sucumbência recursal somente será cabível com a não admissão do recurso ou com sua rejeição unânime. Ainda, restringiu-se o número de recursos com a extinção do agravo retido e dos embargos infringentes.

Tais alterações, de forma geral, foram as principais trazidas pelo CPC/2015, alcançando, no que couber, o sistema recursal dos Juizados Especiais Cíveis.

No mais, apesar de não estar expressa na Lei no 9.099/95 a aplicação subsidiária do Código de Processo Civil aos seus procedimentos, esta deve ser entendida implicitamente, uma vez que

\footnotetext{
${ }^{2}$ Art. $1^{\circ}$. O processo civil será ordenado, disciplinado e interpretado conforme os valores e as normas fundamentais estabelecidos na Constituição da República Federativa do Brasil, observando-se as disposições deste Código.
} 
não se pode ignorar as regras e princípios da legislação. Assim, segundo Kizikoski $(2015$, p. 626) "a incidência supletiva do NCPC dar-se-á apenas para a omissão legislativa das leis que regem os Juizados Especiais".

Os Juizados Especiais Cíveis possuem, como meios próprios de impugnação, o Recurso Inominado (art. 41 da Lei no 9.099/95), os Embargos de Declaração (art. 48 da Lei no 9.099/95) e o Recurso Extraordinário (art. 102, III, da Constituição Federal ${ }^{3}$ ).

O recurso inominado, denominação atribuída pela doutrina, é o recurso cabível contra sentença terminativa ou definitiva no JEC, sendo este semelhante à apelação na Justiça Comum. A sentença será proferida em audiência, começando, a partir de então, a contagem para a interposição do recurso, sendo este de 10 dias, cuja finalidade é rediscutir a decisão proferida pelo juízo a quo.

Ademais, quando a sentença for proferida fora de audiência ou for impugnada por embargos de declaração, deverá ser aplicada a regra do artigo 231, I, do CPC/2015: "salvo disposição em sentido diverso, considera-se dia do começo do prazo: I - a data de juntada aos autos do aviso de recebimento, quando a citação ou a intimação for pelo correio".

A Lei no 9.099/1995 não se manifesta nesse sentido, portanto torna-se viável a aplicação do $\mathrm{CPC} / 2015$, de forma subsidiária, diante da ausência de norma regulamentadora na legislação especial.

A partir da interposição do recurso, o recorrente tem o prazo de 48 horas para a juntada dos preparos das custas e taxas, salvo na hipótese de beneficiário da justiça gratuita, conforme se verifica no art. 54, parágrafo único, da lei. Ocorre que o CPC/2015 trouxe uma inovação referente ao preparo recursal, estabelecendo que a realização do preparo será comprovada no momento da interposição do recurso, sob pena de ser julgado deserto.

Conforme os ensinamentos de Rocha (2015, p. 653):

O sistema adotado pela Lei $n^{\circ}$ 9.099/1995 é melhor do que aquele que existia na versão original do CPC, em que o preparo era feito no prazo de 10 dias da intimação, para tanto. Mas é defasado em relação ao modelo atualmente em vigor, em que a realização do preparo é comprovada no momento da interposição, sob pena de deserção (art.1007 do $\mathrm{CPC} / 2015$ ). Nada impede, entretanto, que o recorrente apresente o comprovante do pagamento do preparo no momento da interposição do recurso.

Dessa forma, é plenamente cabível ao sistema recursal do JEC a comprovação do preparo na interposição do recurso, ficando a critério da parte, sem qualquer prejuízo.

Os embargos de declaração, de acordo Lei no 9.099/1995, serão cabíveis quando a sentença ou acordão apesentar obscuridade, contradição ou omissão, e deverão ser opostos no prazo de 5 dias, suspendendo-se o prazo para interposição de outro recurso.

Todavia o artigo 1.064 do CPC/2015 ampliou a possibilidade de oposição de embargos de declaração no que concerne ao erro material, excluindo a redação do parágrafo único do art. 48 da Lei no 9.099/95. Conforme os ensinamentos de Baggio e Ubaldo, 2015, p. 183: "Tal modificação, a rigor, altera aparentemente pouca coisa. Serve apenas para ampliar a possibilidade de cabimento aos casos de correção de erro material e retirar a hipótese de dúvida."

No mais, o artigo 1.065 do CPC/2015 alterou a redação do artigo 50 da Lei no 9.099/95, dispondo que "Os embargos de declaração interrompem o prazo para a interposição de recurso." Portanto a oposição dos embargos de declaração no JEC passou a interromper o prazo de interposição de outro recurso.

Acrescenta-se, o CPC/2015 trouxe uma mudança no que se refere aos Embargos de Declaração com a finalidade de prequestionamento, considerando que, se o embargante expressou elementos para fim de prequestionamento, assim serão considerados, ainda que não haja manifestação do julgador. Observa-se que, neste ponto, há contradição entre as referidas

\footnotetext{
3 Art. 102. Compete ao Supremo Tribunal Federal, precipuamente, a guarda da Constituição, cabendo-Ihe: III - julgar, mediante recurso extraordinário.
} 
legislações, prevalecendo-se a não aplicabilidade, por se tratar de lei especial - neste sentido o Enunciado 125 do FONAJE ${ }^{4}$.

O Recurso Extraordinário é cabível no JEC, como dispõe o Enunciado 63 do FONAJE: "Contra decisões das Turmas Recursais são cabíveis somente os embargos declaratórios e o Recurso Extraordinário". No mais, a súmula 640 do Supremo Tribunal Federal ainda dispõe: "É cabível recurso extraordinário contra decisão proferida por juiz de primeiro grau nas causas de alçada, ou por turma recursal de Juizado Especial Cível ou Criminal." Assim, continua sendo admissível a interposição de Recurso Extraordinário no JEC, sem modificações. Ressalta-se, o CPC/2015 trouxe, expressamente, o procedimento para atribuição de efeito suspensivo aos recursos extraordinários, segundo o art. $1029, \S 5^{\circ}$ ). Logo, este dispositivo também se aplica ao JEC.

No que tange ao Recurso Especial, não há previsão legal de seu cabimento contra os acórdãos proferidos no JEC. De tal modo, torna-se inaplicável pela da ausência de amparo legal. Neste sentido, dispõe a Súmula 203 do STJ: "Não cabe recurso especial contra decisão proferida por órgão de segundo grau dos Juizados Especiais."

Observa-se que as decisões interlocutórias são irrecorríveis no JEC, exceto quando houver risco de lesão irreparável ou de difícil reparação. Neste sentido, fora editado o Enunciado no 02 do I Encontro do Primeiro Colégio Recursal dos Juizados Especiais Cíveis - SP, estabelecendo que "É admissível, no caso de lesão grave e difícil reparação, o recurso de Agravo de Instrumento no Juizado Especial Cível". Portanto aplicam-se as regras estabelecidas pelo CPC/2015 ao JEC, no que se refere ao recurso de agravo de instrumento, qual sejam, as previstas nos art. 1.015 e seguintes.

Ademais, o Mandado de Segurança é utilizado como sucedâneo recursal das decisões interlocutórias que não cabem agravo de instrumento.

Acrescenta-se, a ação rescisória, embora não sendo recurso, não é cabível no JEC, de acordo com o artigo 59 da Lei no 9.099/95. Eis a redação: "Não se admitirá ação rescisória nas causas sujeitas ao procedimento instituído por esta Lei." Frente a esta proibição, a doutrina criou a querella nulitatis ${ }^{5}$ como meio de resolução das decisões do JEC, que se enquadram nas hipóteses previstas no art. 966 do Código de Processo Civil.

No tocante à Reclamação, esta será cabível sempre que as decisões proferidas nos Juizados Especiais Cíveis se divergirem de orientação jurisprudencial. Neste sentido, fora editada a Resolução no 12, de 14 de dezembro de 2009, pela a Corte Especial do Superior Tribunal de Justiça, prevendo, expressamente, o cabimento de reclamação nos Juizados Especiais Cíveis, não existindo o que se falar em mudanças trazidas pelo CPC/2015.

De forma geral, os prazos para interposição de recursos, passaram a ser contados somente em dias úteis, de acordo com o artigo 219 do Código de Processo Civil. Todavia o referido artigo é incompatível como o enunciado 11 do X FOJESP, que dispõe que "Todos os prazos, no Sistema dos Juizados Especiais, serão contados de forma contínua, excluindo o dia do começo e incluindo o dia do vencimento" (o referido passou a ser o Enunciado 74 do FOJESP). A sustentação é que a contagem prevista, não se aplica ao rito dos Juizados Especiais, haja vista ser incompatível com os princípios fundamentais da simplicidade, da economia processual e, sobretudo, da celeridade. Portanto prevalece a regra prevista Lei $n$ o 9.099/1995, uma vez que se trata de lei especial.

Ademais, no que tange ao juízo de admissibilidade no JEC, é realizado pelo juízo a quo, ao qual incumbe verificar a pertinência, a tempestividade e o prévio pagamento de preparo do recurso. Assim, Segundo Barbosa; Bonin, (2015, p. 640), “A norma, contudo não menciona que o

\footnotetext{
${ }^{4}$ Nos juizados especiais, não são cabíveis embargos declaratórios contra acórdão ou súmula na hipótese do art. 46 da Lei no $9.099 / 1995$, com finalidade exclusiva de prequestionamento, para fins de interposição de recurso extraordinário (XXI Encontro - Vitória/ES).

5 [...] o remédio adequado para impugnar os vícios de atividades (errores in procedendo) mais graves, relacionados com os pressupostos de existência do processo, que não são acobertados pela coisa julgada (Ganem e Zetel, 2012).
} 
juiz a quo fará a admissibilidade recursal, porém é o que se vê na prática, uma vez que o CPC se aplica subsidiariamente ao Juizado Especial Cível." (sic)

Adverte-se, o CPC/2015 suprimiu o juízo de admissibilidade prévio do juízo a quo, passando este a ser analisado pelo juízo ad quem. Entretanto, é sabido que foi sancionada a Lei no 13.256/2016, efetuando uma série de alterações no Novo Código de Processo Civil, inclusive no que se refere ao juízo de admissibilidade, restabelecendo-se, para os juízos a quo, o juízo prévio, como era no CPC de 1973, sob a fundamentação dos ministros do STF e STJ de que isso aumentaria o número de processos nos dois tribunais, comprometendo a agilidade das decisões. Logo, o juízo de admissibilidade previsto no CPC/2015 continua sendo compatível com o disposto na Lei no 9.099/95, uma vez que, em ambos os casos, serão feitos pelo juízo a quo. Portanto não há que se falar em alteração.

\section{CONCLUSÃO}

Conclui-se, as modificações efetivadas pelo novo Código de Processo Civil que não se confrontarem com as regras e princípios orientadores dos Juizados Especiais Cíveis, são perfeitamente adaptáveis ao seu sistema recursal, uma vez que este utiliza-se das regras contidas naquele diploma, subsidiariamente, quando a matéria discutida no caso concreto se faz omissa em sua própria lei.

No mais, o desdobramento do tema fez-se necessário não somente como relevância jurídica para os operadores do direito, mas também como relevância social, haja vista tratar-se de questões novas, pouco investigadas restritivamente.

Finalmente, as informações investigadas destacaram as principais modificações trazidas pela nova legislação, aplicáveis ao sistema recursal do JEC, sendo indispensáveis ao bom andamento da esfera recursal, devendo ser constantemente atualizadas e aperfeiçoadas.

\section{REFERÊNCIAS}

ANDRIGHI, N. Prazos do novo CPC não valem para os Juizados Especiais. JuriNews: notícias jurídicas. 18/03/2016. Disponível em: <http://jurinews.com.br/pra zos-do-novo-cpc-nao-valempara-os-juizados-especiais-diz-corregedora-nacional-de-justica> Acesso em: 19 jul. 2016.

BAGGIO, A. A.; UBALDO. O novo CPC e seus impactos nos recursos dos Juizados Especiais Cíveis. Linhares, E. (coord). Juizados Especiais Cíveis e o Novo CPC. Curitiba: Juruá, 2015, p.183.

BARBOSA; R. V. M.; BONIN, N. M. M. A nova teoria geral dos recursos e as alterações no recurso inominado. Didier J. F. (coord). Juizados Especiais. Salvador: JusPodivm, v.7, 2015, p. 631-632; 640.

BRASIL. Constituição (1988). Constituição da República Federativa do Brasil. 15. ed. In: Curia; Céspedes; Nicoletti. Vade Mecum. São Paulo: Saraiva, 2013.

BRASIL. Lei n. 9.099, de 26 de setembro de 1995. Dispõe sobre os Juizados Especiais Cíveis e Criminais e dá outras providências. 15. ed. In: Curia; Céspedes; Nicoletti. Vade Mecum. São Paulo: Saraiva, 2013.

BRASIL. Novo Código de Processo Civil. In: Curia; Céspedes; Rocha. São Paulo: Saraiva, 2015.

FONAJE. Fórum Nacional de Juizados Especiais. Enunciados atualizados até o XXXIX FONAJE. Disponível em: <http://www.amb.com.br/fonaje/?p=32> Acesso em: 27 jul. 2016. 
GANEM, Fabricio Faroni; ZETTEL, Bernardo. Querela nullitatis e coisa julgada inconstitucional. Revista Jus Navigandi, Teresina, ano 17, n. 3416, 7 nov. 2012. Disponível em: <https://jus.com.br/artigos/22961>. Acesso em: 19 jul. 2016.

KOSIKOSKI, M. S. Os reflexos do NCPC no sistema recursal dos juizados especiais. In: Didier J. F. (coord). Juizados Especiais. Salvador: JusPodivm, v.7, 2015, p. 626.

ROCHA, F. B. Os impactos do novo CPC no recurso inominado dos juizados especiais. Didier J. F. (coord). Juizados Especiais. Salvador: JusPodivm, v.7, 2015, p. 653. 